\title{
Examining the effects of urbanization and industrialization on carbon dioxide emission: Evidence from China's provincial regions
}

\author{
Yang Ding a , Feng Li ${ }^{\mathrm{a}, \mathrm{b}, *}$ \\ a State Key Laboratory of Urban and Regional Ecology, Research Center for Eco-Environmental Sciences, Chinese Academy of Sciences, Beijing 100085, China \\ ${ }^{\mathrm{b}}$ University of Chinese Academy of Sciences, Beijing 100049, China
}

\section{A R T I C L E I N F O}

\section{Article history:}

Received 1 November 2016

Received in revised form

23 February 2017

Accepted 27 February 2017

Available online 3 March 2017

\section{Keywords:}

Carbon

Logarithmic Mean Divisia Index

Decomposition

Urbanization

China

\begin{abstract}
A B S T R A C T
With rapid economic development and expansion of built environment since the year 2000, urbanization has led to great challenge of reduction targets in energy intensity and carbon dioxide emissions. This paper aims to explore the disaggregate driving force of different sectors and investigate the potential of carbon dioxide reduction of them in the context of rapid urbanization. By using the panel datasets at a provincial level in a LMDI (Logarithmic Mean Divisia Index) model, we investigated the effects of various energy-related and socioeconomic factors on regional carbon dioxide emissions in 30 China's provinces from 2000 to 2013. The results show that the factors of economic development are the largest drivers of regional carbon dioxide emissions, compared with the factors of structural change, energy intensity, and social transition. Meanwhile, evidence is found that the urbanization process has contributed to the regional $\mathrm{CO}_{2}$ emissions in China's provinces through a variety of approaches, including changing the energy use characteristics of urban households, transportation, and business sectors. Finally, we found that the changing trend of these influence factors' effect on regional $\mathrm{CO}_{2}$ emissions varied across different provinces, which means there are significant regional heterogeneity in the influence mechanisms of urbanization process on regional $\mathrm{CO}_{2}$ emissions.
\end{abstract}

(c) 2017 Elsevier Ltd. All rights reserved.

\section{Introduction}

With rapid economic development and expansion of the built environment, urbanization has taken place at an unprecedented rate in China since the year 2000. The proportion of the Chinese population living in urban areas reached 56\% in 2015, whereas it was only $36 \%$ in 2000 [16]. Rapid urbanization and industrialization propelled huge economic growth, which was also accompanied by severe increase in fossil energy demand and carbon dioxide emissions.

The relationship between urbanization and regional $\mathrm{CO}_{2}$ emissions has been extensively discussed in the field of energy consumptions and energy-related emissions. Some basic conclusions regarding the impact of urbanization on energy consumption and regional $\mathrm{CO}_{2}$ emissions has been made. Generally, most studies confirm that urbanization and industrialization have significant

\footnotetext{
* Corresponding author. State Key Laboratory of Urban and Regional Ecology, Research Center for Eco-Environmental Sciences, Chinese Academy of Sciences, Beijing 100085, China.

E-mail addresses: yangding@rcees.ac.cn (Y. Ding), lifeng@rcees.ac.cn (F. Li).
}

influence on energy consumption and carbon emissions $[1,12,17,18,22]$. Additionally, some recent literature has shown mixed results about the relationship between urbanization and energy consumption, which means the influence effects of urbanization and industrialization on energy use vary at different development stages and in different regions [12,15]. Although the influence effects of urbanization on energy use and $\mathrm{CO}_{2}$ emissions are generally positive, increasing studies argue that a couple of factors within urbanization process may create potential for the reduction of energy demand.

Consequently, the mechanism how urbanization process influences energy consumption and $\mathrm{CO}_{2}$ emission is dynamic and complex involving both positive and negative effects. In order to investigate the underlying mechanisms, we need to dig into the micro-foundation of urbanization influence on energy use and emissions. First, the changes in regional $\mathrm{CO}_{2}$ emissions related to differing industrial and residential sectors are influenced differently by urbanization processes, for example, urbanization may raise the energy use in urban households but reduce that in the local agricultural sector. Furthermore, from a dynamic view, the 
energy-related emissions in certain sectors may change their trends to be decrease because of technological developments. Understanding the underlying drivers of emission changes in fundamental sectors may help policy makers to adjust industrial policies to limit the incremental environmental damage associated with the rapid economic growth. However, the studies regarding the different effect of urbanization on energy use in various sectors are rather limited $[15,22,26]$.

Another major shortcoming of existing literature is that regional heterogeneity has been scarcely taken into consideration in the discussion of urbanization and regional $\mathrm{CO}_{2}$ emissions [30]. There is a huge difference in population, economic development level, urbanization level, energy efficiency and other indicators in different regions of China [11]. And the heterogeneity of energy consumption patterns and the urbanization process among provinces in China is widely recognized by analysts [15]. Thus there is a necessity for the energy and environmental policy makers to understand the regional differences in the dominant driving forces of regional $\mathrm{CO}_{2}$ emissions and the locus of potential opportunities for $\mathrm{CO}_{2}$ emissions reduction.

This paper provides novel insights to the mechanisms of urbanization influence on regional $\mathrm{CO}_{2}$ emissions by the following: 1 ) clarifying and comparing the contributions of industrial sectors, residential sectors, economic development, and social transition to regional emissions; 2) depicting the dynamic changes in the effect of different types of driving forces on regional $\mathrm{CO}_{2}$ emissions; 3 ) analyzing the regional heterogeneity in influence mechanisms of urbanization on regional emissions; 4) providing policy implications for regional low-carbon development according to the research findings.

\section{Literature review}

A growing body of literature ties urbanization to energy use and carbon dioxide emissions. In general, both positive and negative effects of urbanization on carbon dioxide emissions are found in a variety of studies. For example, many studies confirm a positive correlation between urbanization and carbon dioxide emissions in a cross-country context by adopting cross-country panel data analysis $[4,8,12,13,15]$, while some other research found a negative influence of urbanization on the energy consumption of developed countries [1]. Therefore, the existing literature of relationships between urbanization and carbon dioxide emission is incoherent.

Especially, in the strand of the studies that focus on causal effect of socioeconomic growth on energy use and carbon dioxide emissions in China, consensus either on the existence or on the direction of the causal relationship has not been produced $[23,26]$. This is partly due to differences in methods and sample data, but also reflecting the complex influences of urbanization on energy consumption and carbon dioxide emissions [12]. Thus, recent studies have increasingly focus on the mechanism or key factors of urbanization influence on energy use and carbon dioxide emission.

According to the previous research, urbanization can impact energy use and emissions through multiple channels: transforming production [14,26], changing consumer behavior [31], providing public infrastructures and influencing transport service $[15,16]$. The key point is that the characteristics of urbanization effect on carbon dioxide emissions vary across different industrial sectors of an economy. In other words, there are mixed effects of urbanization on energy use and carbon dioxide emissions. For example, although public infrastructure like central heating increases the energy use by urban residents, it also create potential for reducing energy demand in urban areas [26], because some technological measures including energy-saving buildings, central heating systems improve energy efficiency [15]. Besides, urban dwellers with enhancing awareness of energy-saving may shift their consumption patterns towards green products [28]. What's more, even though the industrial production process in cities gives rise to enormous energy consumption, the compact city theory argues that high urban density allows cities to exploit economies of scale for urban public infrastructures by reducing car dependency, travel distance, the transmission and distribution losses of electricity supply, together resulting in a reduction of energy consumption $[15,26]$.

The decomposition analysis, furthermore, allows researchers to investigate the socioeconomic driven forces of carbon dioxide emission, which offers clues of low-carbon development policies. Most of them confirm that the main influencing factors are energy intensity, energy mix, gross domestic product structure, and GDP itself $[3,4,10,22,30,32,33]$. Wang et al. [19] decomposed the carbon emissions into population, GDP per capita, energy consumption intensity and energy consumption structure and concluded that the total theoretical decrease of $\mathrm{CO}_{2}$ emission from 1957 to 2000 can be attributed to fossil fuel mix and renewable energy penetration. Besides, some studies argued that the reduction in $\mathrm{CO}_{2}$ emissions can be attributed to the reduced energy intensity and fuel switching and renewable energy penetration. Meanwhile, some researches attached great importance to the adjustment of industrial structure for the process of developing low-carbon emission industries $[14,21,24]$.

The current analysis of the mechanism or key factors of urbanization influence on energy use and carbon dioxide emission, however, is inadequate. The reason is that the effect of different industrial sectors on carbon dioxide emissions is significantly asymmetrical, meanwhile urbanization process leads to different changes in these sectors. In other words, only have the distinguished contributions of various sectors on $\mathrm{CO}_{2}$ emissions been discovered and compared empirically, could we explain how urbanization triggers changes in the energy use in the key sectors, which in turn affect regional carbon dioxide emissions.

Another cause of different urbanization influence on carbon dioxide emission is regional heterogeneity [11]. However, the studies on the urbanization effect on energy-related $\mathrm{CO}_{2}$ emission in Chinese provinces are incomplete and fragmented. This fragmentation likely stems from the fact that researchers are interested in a broad range of specific questions in particular research contexts and have tackled a variety of sector-specific $[6,9,17,18,25,27]$ and region-specific research $[17,18,21,24,32,33]$, for example, the carbon emission trading in Guangdong Province [20], the energy efficiency in Shandong Province [7], and the industrial restructuring in Jiangsu Province [29]. The fragmented research landscape raises up many fundamental questions for scholars of this field. During the rapid urbanization process, which industrial sector in which region has performed significant changes in terms of contributing to regional carbon dioxide emissions? How does urbanization effect on carbon dioxide emissions vary across the regions in China? What are the reasons for the regional heterogeneity of urbanization effect on $\mathrm{CO}_{2}$ emissions?

From the practical perspective, regional heterogeneities play important role in making regional low-carbon policies. That is because there is a huge difference in population, economic development level, urbanization level, energy efficiency and other 
indicator in different regions of China, which result in different carbon emission per capita. Besides, the energy intensity and carbon dioxide emission intensity among various industries including the primary sector, production, construction, and transportation are seriously different. Thus, revealing these disaggregated impacts on energy use in different sectors and different regions could provide a further understanding regarding mechanisms of urbanization impact on energy-related carbon emissions in China.

To sum up, there are still three shortcomings of existing literature, which have left important research questions unexplored. First, the existing literature of relationships between urbanization and carbon dioxide emission is incoherent, which calls for a reconciliation by explaining the mixed effect of urbanization on carbon dioxide emissions. Second, the current analysis of the mechanism or key factors of urbanization influence on energy use and carbon dioxide emission is inadequate, requiring a more detailed study on the comparison on the effects of different sectors on carbon dioxide emissions. Third, the studies on the urbanization effect on energy-related $\mathrm{CO}_{2}$ emission in Chinese provinces are incomplete and fragmented, which asks for a comprehensive analysis of all the provinces for the regional disparities of urbanization influence on carbon dioxide emissions.

\section{Methodology and data collection}

In this study, LMDI (Logarithmic Mean Divisia index) has been chosen in the energy consumption and carbon dioxide emissions analysis $[3,5,10,22,32,33]$, due to its robust theoretical foundation and the ability to enable the decomposition of plenty of influence factors. In order to explore the mechanisms of urbanization influence on regional $\mathrm{CO}_{2}$ emissions in depth, this research addresses seven sectors for a decomposition analysis: agriculture, production, construction, transportation, business, urban households, and rural households. Specifically, we explore the contribution of energy- according to the central focus of this research, we collect macrosocioeconomic data of urbanization, macro-economic development, household income, industrial structure from the Chinese Statistic Yearbook from 2001 to 2014.

Second, the emission inventories of China's provinces from 2000 to 2013 are collected from the China Emission Accounts and Datasets (CEADs). CEADs provides accurate and most up-to-date emission data of China at both national and provincial levels. All datasets published by CEADs are the results of current research projects funded by Research Council UK, Newton Fund, the National Natural Science Foundation of China, Chinese Academy of Sciences.

The province-level carbon dioxide emission inventories used in this study are compiled based on latest energy data revision (2015) by Chinese Statistics Bureau, according to IPCC Sectoral Emission Accounting Approach in the format of 45 production sectors and 2 residential sectors. We then combine the 45 production sectors into 5 industrial categories: agriculture, production, construction, transportation, services. Thus, together with the emission inventories in two residential sectors-urban and rural households, there are the compiled province-level carbon dioxide emission inventories in 7 sectors in total.

Furthermore, in each industrial and residential sector, the emission inventories are calculated based on various fuel combustion within the regional administrative boundary. Specifically, there are more than 20 fuel types: raw coal, cleaned coal, other washed coal, briquettes, coke, coke oven gas, other gas, other coking products, crude oil, gasoline, kerosene, diesel oil, fuel oil, LPG, refinery gas, other petroleum product, natural gas.

\subsection{The contribution of determinants in each sector to the total regional emission}

Total carbon dioxide emissions at the provincial region level can be expressed in the following way:

$$
\begin{aligned}
& C_{i}=\sum_{j=1}^{7} \sum_{k=1}^{20} C_{i j}=\sum_{k=1}^{20} C_{\mathrm{i} 1 \mathrm{k}}+\sum_{k=1}^{20} C_{\mathrm{i} 2 \mathrm{k}}+\sum_{k=1}^{20} C_{\mathrm{i} 3 \mathrm{k}}+\sum_{k=1}^{20} C_{\mathrm{i} 4 \mathrm{k}}+\sum_{k=1}^{20} C_{\mathrm{i} 5 \mathrm{k}}+\sum_{k=1}^{20} C_{\mathrm{i} 6 \mathrm{k}}+\sum_{k=1}^{20} C_{\mathrm{i} 7 \mathrm{k}} \\
& =\sum_{k=1}^{20} \frac{C_{i 1 k}}{E_{i 1 k}} \cdot \frac{E_{i 1 k}}{E_{i 1}} \cdot \frac{E_{i 1}}{Y_{i 1}} \cdot \frac{Y_{i 1}}{Y_{i}} \cdot \frac{Y_{i}}{P_{i}} \cdot P_{i}+\sum_{k=1}^{20} \frac{C_{i 2 k}}{E_{i 2 k}} \cdot \frac{E_{i 2 k}}{E_{i 2}} \cdot \frac{E_{i 2}}{Y_{i 2}} \cdot \frac{Y_{i 2}}{Y_{i}} \cdot \frac{Y_{i}}{P_{i}} \cdot P_{i} \\
& +\sum_{k=1}^{20} \frac{C_{i 3 k}}{E_{i 3 k}} \cdot \frac{E_{i 3 k}}{E_{i 3}} \cdot \frac{E_{i 3}}{Y_{i 3}} \cdot \frac{Y_{i 3}}{Y_{i}} \cdot \frac{Y_{i}}{P_{i}} \cdot P_{i}+\sum_{k=1}^{20} \frac{C_{i 4 k}}{E_{i 4 k}} \cdot \frac{E_{i 4 k}}{E_{i 4}} \cdot \frac{E_{i 4}}{Y_{i 4}} \cdot \frac{Y_{i 4}}{Y_{i}} \cdot \frac{Y_{i}}{P_{i}} \cdot P_{i} \\
& +\sum_{k=1}^{20} \frac{C_{i 5 k}}{E_{i 5 k}} \cdot \frac{E_{i 5 k}}{E_{i 5}} \cdot \frac{E_{i 5}}{Y_{i 5}} \cdot \frac{Y_{i 5}}{Y_{i}} \cdot \frac{Y_{i}}{P_{i}} \cdot P_{i}+\sum_{k=1}^{20} \frac{C_{i 6 k}}{E_{i 6 k}} \cdot \frac{E_{i 6 k}}{E_{i 6}} \cdot \frac{E_{i 6}}{U H I_{i}} \cdot A U I_{i} \cdot \frac{U P_{i}}{P_{i}} \cdot P_{i} \\
& +\sum_{k=1}^{20} \frac{C_{i 7 k}}{E_{i 7 k}} \cdot \frac{E_{i 7 k}}{E_{i 7}} \cdot \frac{E_{i 7}}{R H I_{i}} \cdot A R I_{i} \cdot R P_{i}
\end{aligned}
$$

related and socioeconomic driving factors to the changes in regional $\mathrm{CO}_{2}$ emissions within a certain period of time.

\subsection{Data set}

In this study, we collect data of a broad range of themes. First,
In Eq. (1), $i$ denotes a specific Chinese province; $j$ denotes a specific sector; specifically, $j=1$ for agriculture sector; $j=2$ for production sector; $j=3$ for construction sector; $j=4$ for transportation sector; $j=5$ for business sector; $j=6$ for urban household sector; $j=7$ for rural household sector; $k$ denotes a certain type of 
Table 1

The Implication of each variable in Eq. (1).

\begin{tabular}{|c|c|c|c|}
\hline Index & Definition & Index & Definition \\
\hline$C_{i j k}$ & The carbon dioxide emission of each type of fuel in each sector in each region & $E_{i j k}$ & The amount of energy use of each type of fuel in each sector in each region \\
\hline$Y_{i j}$ & The gross domestic output of each sector in each region & $P_{i}$ & The population in each region \\
\hline$U_{H}$ & The total income of urban residents in each region & $A U I_{i}$ & The average income of urban residents in each region \\
\hline$U P_{i}$ & The civic population in each region & $\mathrm{RHI}_{\mathrm{i}}$ & The total income of rural residents in each region \\
\hline$A R I_{i}$ & The average income of rural residents in each region & $R P_{i}$ & The rural population in each region \\
\hline
\end{tabular}

fuel. The implications of other variables are described in Table 1.

The emission can be further expressed as:

$$
\begin{aligned}
& C_{i}=\sum_{k=1}^{20} C E_{\mathrm{i} 1 \mathrm{k}} \cdot E S_{i 1 k} \cdot E I A_{i} \cdot Y S_{i 1} \cdot Y P_{i} \cdot P_{i}+\sum_{k=1}^{20} C E_{\mathrm{i} 2 \mathrm{k}} \cdot E S_{i 2 k} \cdot E I P_{i} \cdot Y S_{i 2} \cdot Y P_{i} \cdot P_{i} \\
& +\sum_{k=1}^{20} C E_{\mathrm{i} 3 \mathrm{k}} \cdot E S_{i 3 k} \cdot E I C_{i} \cdot Y S_{i 3} \cdot Y P_{i} \cdot P_{i}+\sum_{k=1}^{20} C E_{\mathrm{i} 4 \mathrm{k}} \cdot E S_{i 4 k} \cdot E I T_{i} \cdot Y S_{i 4} \cdot Y P_{i} \cdot P_{i} \\
& +\sum_{k=1}^{20} C E_{\mathrm{i} 5 \mathrm{k}} \cdot E S_{i 5 k} \cdot E I S_{i} \cdot Y S_{i 5} \cdot Y P_{i} \cdot P_{i}+\sum_{k=1}^{20} C E_{\mathrm{i} 6 \mathrm{k}} \cdot E S_{i 6 k} \cdot E I U_{i} \cdot A U I_{i} \cdot U R_{i} \cdot P_{i} \\
& +\sum_{k=1}^{20} C E_{\mathrm{i} 7 \mathrm{k}} \cdot E S_{i 7 k} \cdot E I R_{i} \cdot A R I_{i} \cdot R P_{i}
\end{aligned}
$$

The implications of variables in Eq. (2) are described in Table 2. The increment of regional $\mathrm{CO}_{2}$ emissions can be decomposed as

$$
\begin{aligned}
\Delta C_{i}= & C_{i}^{T}-C_{i}^{0} \\
= & \Delta C_{i, C E}+\Delta C_{i, E S}+\Delta C_{i, E I A}+\Delta C_{i, Y S}+\Delta C_{i, Y P}+\Delta C_{i, P}+\Delta C_{i, E I P} \\
& +\Delta C_{i, E I C}+\Delta C_{i, E I T}+\Delta C_{i, E I S}+\Delta C_{i, E I U}+\Delta C_{i, A U I}+\Delta C_{i, U R} \\
& +\Delta C_{i, E I R}+\Delta C_{i, A R I}+\Delta C_{i, R P}
\end{aligned}
$$

Following the LMDI method proposed by Ang [2]; the effect of each factor can be calculated as

\section{Results}

The contribution of key factors to the regional carbon dioxide emissions in each region from 2000 to 2013 is shown in Tables 3 and 4 . There are fourteen factors reported. First, we show the results of the energy intensity in each sector: the energy intensity in agriculture (EIA), in production (EIP), in construction (EIC), in transportation (EIT), in business and service (EIS), in urban households (EIU), and in rural households (EIR). Second, we report the contribution of structural change factors: the energy consumption structure (ES) and industrial structure (YS). Third, the economic development factors' effect is indicated by the gross domestic products per capita $(Y P)$, and the average income of both urban

$$
\begin{aligned}
& \Delta C_{i}=\sum_{j=1}^{7} \sum_{k=1}^{20}\left(\frac{C_{i j k}^{T}-C_{i j k}^{0}}{\ln C_{i j k}^{T}-\ln C_{i j k}^{0}} \ln \left(\frac{C E_{i j k}^{T}}{C E_{i j k}^{0}}\right)\right)+\sum_{j=1}^{7} \sum_{k=1}^{20}\left(\frac{C_{i j k}^{T}-C_{i j k}^{0}}{\ln C_{i j k}^{T}-\ln C_{i j k}^{0}} \ln \left(\frac{E S_{i j k}^{T}}{E S_{i j k}^{0}}\right)\right)+\sum_{j=1}^{5}\left(\frac{C_{i j}^{T}-C_{i j}^{0}}{\ln C_{i j}^{T}-\ln C_{i j}^{0}} \ln \left(\frac{Y S_{i j}^{T}}{Y S_{i j}^{0}}\right)\right) \\
& +\sum_{j=1}^{5}\left(\frac{C_{i j}^{T}-C_{i j}^{0}}{\ln C_{i j}^{T}-\ln C_{i j}^{0}} \ln \left(\frac{Y P_{i j}^{T}}{Y P_{i j}^{0}}\right)\right)+\frac{C_{i 1}^{T}-C_{i 1}^{0}}{\ln C_{i 1}^{T}-\ln C_{i 1}^{0}} \ln \left(\frac{E I A_{i}^{T}}{E I A_{i}^{0}}\right)+\frac{C_{i 2}^{T}-C_{i 2}^{0}}{\ln C_{i 2}^{T}-\ln C_{i 2}^{0}} \ln \left(\frac{E I P_{i}^{T}}{E I P_{i}^{0}}\right) \\
& +\frac{C_{i 3}^{T}-C_{i 3}^{0}}{\ln C_{i 3}^{T}-\ln C_{i 3}^{0}} \ln \left(\frac{E I C_{i}^{T}}{E I C_{i}^{0}}\right)+\frac{C_{i 4}^{T}-C_{i 4}^{0}}{\ln C_{i 4}^{T}-\ln C_{i 4}^{0}} \ln \left(\frac{E I T_{i}^{T}}{E I T_{i}^{0}}\right)+\frac{C_{i 5}^{T}-C_{i 5}^{0}}{\ln C_{i 5}^{T}-\ln C_{i 5}^{0}} \ln \left(\frac{E I S_{i}^{T}}{E I S_{i}^{0}}\right) \\
& +\frac{C_{i 6}^{T}-C_{i 6}^{0}}{\ln C_{i 6}^{T}-\ln C_{i 6}^{0}} \ln \left(\frac{E I U_{i}^{T}}{E I U_{i}^{0}}\right)+\frac{C_{i 7}^{T}-C_{i 7}^{0}}{\ln C_{i 7}^{T}-\ln C_{i 7}^{0}} \ln \left(\frac{E I R_{i}^{T}}{E I R_{i}^{0}}\right)+\frac{C_{i 6}^{T}-C_{i 6}^{0}}{\ln C_{i 6}^{T}-\ln C_{i 6}^{0}} \ln \left(\frac{A U I_{i}^{T}}{A U I_{i}^{0}}\right) \\
& +\frac{C_{i 6}^{T}-C_{i 6}^{0}}{\ln C_{i 6}^{T}-\ln C_{i 6}^{0}} \ln \left(\frac{U R_{i}^{T}}{U R_{i}^{0}}\right)+\frac{C_{i 7}^{T}-C_{i 7}^{0}}{\ln C_{i 7}^{T}-\ln C_{i 7}^{0}} \ln \left(\frac{A R I_{i}^{T}}{A R I_{i}^{0}}\right)+\frac{C_{i 7}^{T}-C_{i 7}^{0}}{\ln C_{i 7}^{T}-\ln C_{i 7}^{0}} \ln \left(\frac{R P_{i}^{T}}{R P_{i}^{0}}\right)+\frac{C_{i}^{T}-C_{i}^{0}}{\ln C_{i}^{T}-\ln C_{i}^{0}} \ln \left(\frac{P_{i}^{T}}{P_{i}^{0}}\right)
\end{aligned}
$$


Table 2

Implications of each variable in Eq. (2).

\begin{tabular}{|c|c|c|c|}
\hline Index & Definition & Index & Definition \\
\hline$C E_{i j k}=\frac{C_{i j k}}{E_{i j k}}$ & Carbon emission coefficient of each type of fuel & $E S_{i j k}=\frac{E_{i j k}}{E_{i j}}$ & The proportion of consumption of each type of fuel \\
\hline$E I A_{i}=\frac{E_{i 1}}{Y_{i 1}}$ & Energy intensity in agricultural sector & $Y S_{i j}=\frac{Y_{i j}}{Y_{i}}$ & The proportion of output of each sector \\
\hline$Y P_{i}=\frac{Y_{i}}{P_{i}}$ & The gross domestic output per capita & $E I P_{i}=\frac{E_{i 2}}{Y_{i 2}}$ & The energy intensity in production sector \\
\hline$E I C_{i}=\frac{E_{i 3}}{Y_{i 3}}$ & The energy intensity in construction sector & $E I T_{i}=\frac{E_{i 4}}{Y_{i 4}}$ & The energy intensity in transportation sector \\
\hline$E I S_{i}=\frac{E_{i 5}}{Y_{i 5}}$ & The energy intensity in business sector & $E I U_{i}=\frac{E_{i 6}}{U H I_{i}}$ & The energy intensity of the urban households \\
\hline$U R_{i}=\frac{U P_{i}}{P_{i}}$ & The rate of urbanization & $E I R_{i}=\frac{E_{i 7}}{R H I_{i}}$ & The energy intensity of the rural households \\
\hline
\end{tabular}

households (AUI) and rural households (ARI). Finally, social factors including the urbanization rate $(U R)$ and the regional population $(P)$ are reported.

Besides, the rural population $(R P)$ and the carbon emission coefficient (CE) are not reported in Tables 3 and 4 for several reasons. As the focus of this study is concerning the effect of urbanization processes on regional $\mathrm{CO}_{2}$ emissions, the discussion of $R P$ is of less interest. Furthermore, because the value of the factor $C E$ for each type of fuel is a constant, which is provided by 2006 IPCC Guidelines for National Greenhouse Gas Inventories, the contribution of the factor $C E$ to the increment of regional carbon dioxide emissions is zero for all the provinces.

\subsection{Effect of energy-related factors on regional $\mathrm{CO}_{2}$ emission}

\subsubsection{Effect of changes in the energy consumption structure}

We begin with the discussion of the factor, energy consumption structure in China. Overall, as shown in Fig. 1, the total consumption of China has been growing steadily for the thirteen years, peaking at 84064 PJ in the year of 2013, while the structure of different energy use changed during this period in several phases. First, although the

Table 3

The contribution of energy-related and structural factors in each region (Unit: Mt $\mathrm{CO}_{2}$ ).

\begin{tabular}{llllllll}
\hline & $E I A$ & EIP & EIC & EIT & EIS & ES & YS \\
\hline Beijing & 6.23 & 229.52 & 6.04 & 77.28 & 49.77 & -2.8 & 444.13 \\
Tianjin & 5.19 & 416.44 & 10.16 & 77.77 & 22.06 & -22.1 & 559.28 \\
Hebei & 13.25 & 2193.80 & 5.06 & 61.85 & 43.17 & -38.0 & 2563.31 \\
Shanxi & 24.42 & 1388.84 & 10.27 & 59.46 & 32.05 & -34.9 & 1776.37 \\
Inner Mongolia & 29.88 & 1269.72 & 17.70 & 83.94 & 70.89 & -12.4 & 1897.25 \\
Liaoning & 20.57 & 1399.89 & 9.25 & 115.13 & 30.66 & -23.5 & 1829.18 \\
Jilin & 14.18 & 573.42 & 7.47 & 39.83 & 37.05 & 1.4 & 859.11 \\
Heilongjiang & 26.93 & 778.92 & 0.79 & 65.08 & 42.98 & -6.8 & 908.61 \\
Shanghai & 7.19 & 609.08 & 12.60 & 190.82 & 41.39 & -21.9 & 880.28 \\
Jiangsu & 26.75 & 1879.46 & 4.25 & 106.28 & 12.64 & -41.6 & 2197.43 \\
Zhejiang & 33.27 & 1078.61 & 15.37 & 89.19 & 25.22 & -30.9 & 1357.62 \\
Anhui & 14.72 & 727.10 & 6.91 & 40.80 & 12.77 & -18.8 & 1080.00 \\
Fujian & 18.11 & 568.07 & 5.35 & 58.60 & 19.59 & -11.5 & 727.18 \\
Jiangxi & 9.23 & 419.81 & 1.18 & 42.33 & 7.22 & -2.9 & 592.55 \\
Shandong & 45.26 & 2356.00 & 23.47 & 196.33 & 70.65 & 60.9 & 2826.70 \\
Henan & 22.17 & 1502.32 & 2.87 & 75.20 & 13.40 & -1.5 & 1905.82 \\
Hubei & 30.20 & 823.05 & 16.98 & 103.29 & 49.52 & -18.9 & 1180.58 \\
Hunan & 30.76 & 643.41 & 10.56 & 75.23 & 39.34 & 11.1 & 961.29 \\
Guangdong & 21.28 & 1324.58 & 7.81 & 218.80 & 35.61 & -17.0 & 1831.12 \\
Guangxi & 5.19 & 408.50 & 1.31 & 53.96 & 13.59 & 2.9 & 605.26 \\
Hainan & 5.09 & 50.50 & 0.84 & 21.67 & 2.81 & 11.1 & 85.64 \\
Chongqing & 22.73 & 316.19 & 5.53 & 45.88 & 9.25 & -15.8 & 535.98 \\
Sichuan & 19.77 & 771.37 & 10.38 & 70.79 & 47.12 & -12.7 & 1063.91 \\
Guizhou & 18.70 & 498.10 & 3.12 & 38.67 & 67.06 & 2.5 & 780.76 \\
Yunnan & 18.85 & 514.36 & 6.17 & 71.86 & 12.60 & 4.6 & 610.25 \\
Shaanxi & 6.48 & 528.09 & 10.72 & 52.64 & 25.17 & 21.7 & 770.40 \\
Gansu & 6.14 & 301.55 & 3.94 & 26.71 & 6.09 & -9.9 & 397.28 \\
Qinghai & 1.09 & 92.40 & 1.56 & 7.54 & 9.62 & -2.8 & 131.28 \\
Ningxia & 3.06 & 75.53 & 6.87 & 9.56 & 7.95 & 5.1 & 363.09 \\
Xinjiang & 19.73 & 573.70 & 4.77 & 48.35 & 21.81 & -6.8 & 670.51 \\
\hline & & & & & & &
\end{tabular}

consumption of raw coal slightly increased from 2000 to 2013, reaching $21523 \mathrm{PJ}$, the proportion of raw coal in the total energy use consistently decreased from $36.67 \%$ to $28.44 \%$. At the same time, cleaned coal and coke was consumed to a larger extent, which was more environmental friendly efficient than raw coal with a rise from $1.2 \%$ to $1.75 \%$ and from $11.92 \%$ to $17.21 \%$, respectively. Meanwhile, the consumption of various oil fuels was all consumed to a less extent. For instance, the consumption of crude oil remained almost the same level during those years and it took up only $0.35 \%$ of the total energy use in 2013 , compared with the figure of $1.04 \%$ in 2000.

However, the proportion of clean and renewable energy consumption has increased seriously between 2000 and 2013. Especially, the use of natural gas increased from 813 PJ to 4407 PJ, with a rise in its proportion from $3.19 \%$ to $5.82 \%$, the consumption of nonfossil heat grew up to $3604 \mathrm{PJ}$ while it was only $1444 \mathrm{PJ}$ at the beginning. The most impressive change was concerning to nonfossil electricity for the fact that the total consumption climbed from 4512 PJ to 18382 PJ, taking up more than $24 \%$ of the national energy use. The electricity generation sector has always been the largest contributor to the national $\mathrm{CO}_{2}$ emissions, so decoupling electricity and fossil fuel plays a most significant role in the measures of $\mathrm{CO}_{2}$ reduction.

The changes in energy consumption structure have important effect on the carbon dioxide emissions in China. Furthermore, the impact of changes in energy consumption structure varies across the provincial regions (Fig. 2). Overall, the contributions of transitions in energy structure were negative in most regions except Shandong, Shaanxi, Hunan, Hainan, Ningxia, Yunnan, Guangxi, and Guizhou. To be specific, this factor posed the most positive effect on the regional carbon dioxide emission in Shandong, making a 60.86 Mt contribution, however, it marked a -41.59 Mt contribution to the emission in Jiangsu. It showed that as the two largest $\mathrm{CO}_{2}$ contributors Jiangsu implemented effective measures to transit to low-carbon energies, while the energy consumption structure still tended to provide high carbon intensity to the industrial energy use. Besides, the energy structure transition created remarkable reduction of carbon dioxide emission in Hebei, Shanxi, Zhejiang, Liaoning, Tianjin, Shanghai, Hubei, Anhui, Guangdong, Chongqing, Sichuan, Inner Mongolia, Fujian, Gansu, Heilongjiang, and Xinjiang, showing that the adjustment of energy structure was proved to be an effective method for developing low-carbon economy in these regions. But, the changes in energy structure did not make obvious impact to regions such as Jilin, Henan, Qinghai, Beijing, Jiangxi.

\subsubsection{Effect of energy intensity in a variety of economic sectors}

In order to capture the characteristics of each economic sector's effect on carbon dioxide emissions, we compare the contribution of energy intensity of different economic sectors across the time period from 2000 to 2013.

Overall, the energy intensity in each sector posed positive 
Table 4

Contribution of socioeconomic factors in each region (Unit: $\mathrm{Mt}_{\mathrm{CO}_{2}}$ ).

\begin{tabular}{llllllll} 
& $Y P$ & $U R$ & $P$ & $A U I$ & $A R I$ & $E I U$ & EIR \\
\hline Beijing & 619.06 & 5.83 & 550.68 & 53.46 & 20.40 & 38.80 & 15.41 \\
Tianjin & 760.44 & 5.39 & 626.45 & 18.50 & 6.56 & 13.61 & 4.86 \\
Hebei & 3361.86 & 2.64 & 2653.35 & 72.33 & 82.39 & 46.17 & 74.22 \\
Shanxi & 2451.96 & 3.03 & 1836.59 & 45.44 & 62.61 & 30.32 & 48.21 \\
Inner Mongolia & 2725.61 & 3.47 & 1863.91 & 47.59 & 29.53 & 47.26 & 35.06 \\
Liaoning & 2488.51 & 4.17 & 1884.87 & 50.62 & 18.78 & 36.36 & 14.54 \\
Jilin & 1168.26 & 3.66 & 855.45 & 31.72 & 9.19 & 21.28 & 8.40 \\
Heilongjiang & 1238.31 & 3.77 & 1011.73 & 54.15 & 6.59 & 41.99 & 6.42 \\
Shanghai & 1121.48 & 6.02 & 1008.93 & 31.37 & 13.46 & 25.01 & 10.04 \\
Jiangsu & 3095.76 & 3.64 & 2317.12 & 47.25 & 8.81 & 34.90 & 8.71 \\
Zhejiang & 1839.21 & 3.91 & 1464.15 & 38.39 & 25.95 & 28.29 & 22.68 \\
Anhui & 1441.02 & 2.60 & 1062.26 & 36.42 & 16.99 & 25.75 & 17.61 \\
Fujian & 976.99 & 3.47 & 754.14 & 20.89 & 13.22 & 14.00 & 12.97 \\
Jiangxi & 777.24 & 2.67 & 580.51 & 19.28 & 14.80 & 12.30 & 13.80 \\
Shandong & 3866.21 & 3.20 & 2965.79 & 71.07 & 34.81 & 57.21 & 32.98 \\
Henan & 2554.32 & 2.28 & 1902.06 & 52.46 & 62.99 & 32.43 & 50.56 \\
Hubei & 1637.23 & 3.22 & 1222.96 & 49.10 & 35.01 & 37.41 & 30.00 \\
Hunan & 1312.04 & 2.68 & 953.34 & 15.73 & 34.37 & 15.40 & 33.72 \\
Guangdong & 2467.54 & 4.28 & 2015.62 & 92.97 & 33.71 & 72.82 & 30.96 \\
Guangxi & 827.19 & 2.46 & 606.23 & 24.20 & 5.23 & 17.08 & 5.22 \\
Hainan & 122.42 & 3.23 & 91.74 & 2.81 & 0.44 & 2.16 & 0.45 \\
Chongqing & 747.83 & 3.25 & 530.90 & 14.31 & 17.62 & 11.23 & 15.60 \\
Sichuan & 1448.08 & 2.46 & 1074.00 & 49.25 & 53.98 & 37.21 & 44.10 \\
Guizhou & 1144.27 & 2.03 & 775.00 & 15.88 & 71.40 & 12.32 & 53.13 \\
Yunnan & 872.33 & 2.17 & 654.60 & 14.41 & 29.35 & 10.56 & 23.87 \\
Shaanxi & 1101.17 & 2.82 & 786.50 & 50.52 & 15.14 & 35.73 & 14.65 \\
Gansu & 552.21 & 2.21 & 407.76 & 10.16 & 26.85 & 6.47 & 20.86 \\
Qinghai & 177.48 & 2.84 & 137.70 & 11.95 & 7.52 & 9.24 & 5.94 \\
Ningxia & 531.47 & 2.97 & 379.58 & 9.24 & 5.45 & 0.00 & 0.00 \\
Xinjiang & 909.48 & 2.72 & 718.12 & 28.34 & 24.40 & 21.22 & 16.65 \\
\hline & & & & & & &
\end{tabular}

effects on the national $\mathrm{CO}_{2}$ emissions (Fig. 3). The rank of average impacts of energy intensity in all the sectors are as follows: Production, Transportation, Urban households, Rural households, Business, Agriculture, Construction. It can be seen that the factor of energy intensity in the production sector plays the dominating role in the impacts on the national $\mathrm{CO}_{2}$ emissions. Besides, the impacts of energy intensity in the primary sector gradually decrease from 2000 to 2013. The impacts of other factors seemed to have remained across these years. From a regional perspective, the influence effect of energy intensity in production sector on $\mathrm{CO}_{2}$ emissions was much higher than that of other sectors. Meanwhile there are severe regional disparities of the impact resulted by this factor. Especially, the average contribution is more than $393 \mathrm{Mt}$ in Shandong and only 8.42 in Hainan from 2000 to 2013. Besides, the contribution of the transportation sector was generally following that of the production sector. To be specific, it made a $32 \mathrm{Mt}$ contribution to the emissions in Shanghai and took up about 77.28 Mt contribution to the emissions in Beijing from 2000 to 2013, which are relatively higher among the sectors, indicating that the increasing transport demand accompanied with the urbanization process has already become one of the dominating driven factors to the regional $\mathrm{CO}_{2}$ emissions (see Fig. 4). The business sector played an important role in the impact on regional $\mathrm{CO}_{2}$ emissions in some regions, especially in the developed regions such as Beijing, Shanghai, Zhejiang, and Jiangsu, indicated by the relatively high contribution of the business sector in these regions.

The energy intensity in each sector was declining in most regions, for example, during the period between 2000 and 2013, the energy intensity dropped from 0.23 to $0.12 \mathrm{PJ} / 10^{8}$ yuan in the primary sector of Beijing, from 1.34 to $0.19 \mathrm{PJ} / 10^{8}$ yuan in the production sector of Chongqing, and from 0.66 to $0.06 \mathrm{PJ} / 10^{8}$ yuan in the business sector of Tianjin. The declining trend also happened in the household sector, especially when the energy intensity of urban households living in Anhui dropped more than $680 \mathrm{PJ} / 10^{8}$ yuan during this period. However, in the transportation sector, the energy intensity experienced a slight rise from 0.21 to $0.29 \mathrm{PJ} / 10^{8}$ yuan in Beijing, from 0.06 to $0.07 \mathrm{PJ} / 10^{8}$ yuan in Tianjin, and from 0.01 to $0.06 \mathrm{PJ} / 10^{8}$ yuan in Shandong. In the rural areas of some provinces, the energy intensity in residents' living sector also grew slowly, for example, it rose from 121 to $325 \mathrm{PJ} / 10^{8}$ yuan in Heilongjiang and from 387 to $582 \mathrm{PJ} /$ $10^{8}$ yuan in Fujian.

\subsection{Effects of social and economic factors}

\subsubsection{Urbanization}

The focus of this study is the effect of urbanization process on the carbon dioxide emission in different regions. As shown in Fig. 5,

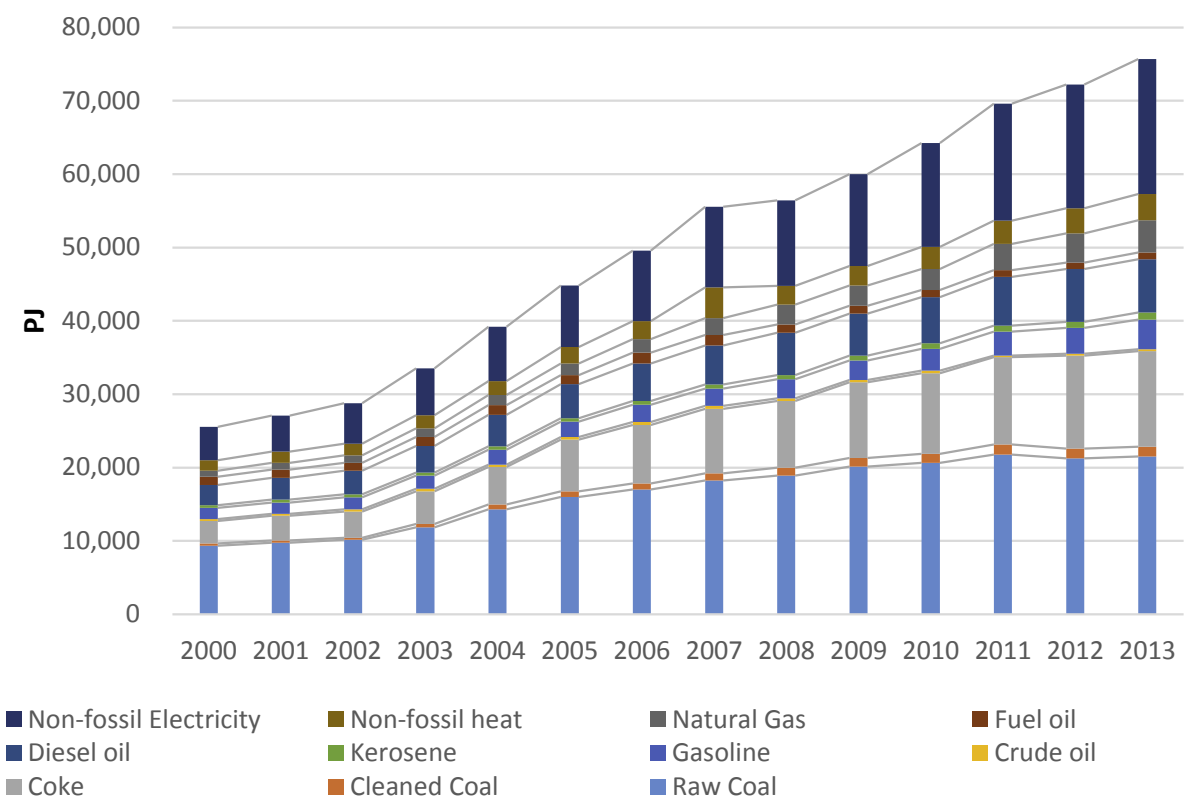

Fig. 1. Changes in the national energy consumption structure from 2000 to 2013. 
The contribution of changes in energy structure to the emissions in each region

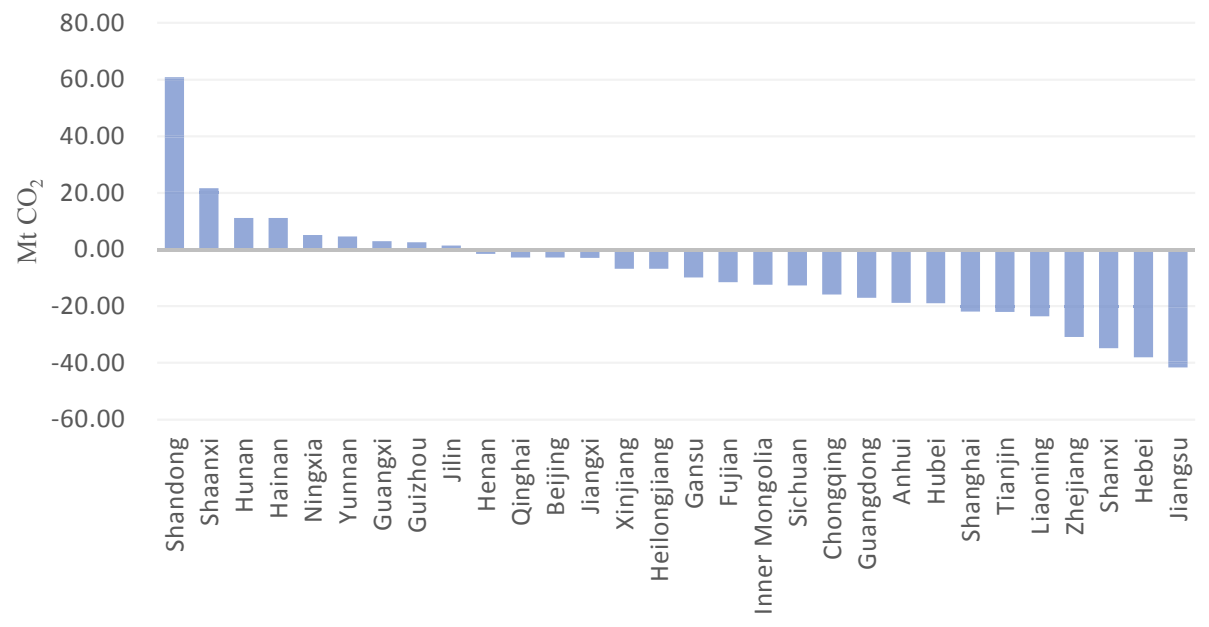

Fig. 2. The contribution of energy structure change in each region from 2000 to 2013.

the urbanization process impacted the emissions in different regions to various extents, with the average contribution varying from 1.7 Mt to $14 \mathrm{Mt}$. Generally, the influence effects in each period from 2008 to 2013 are close to each other in each region, but the impact of urbanization from 2008 to 2013 is obviously bigger than that in earlier period from 2000 to 2006 . There are those regions where the impact of urbanization on regional $\mathrm{CO}_{2}$ emissions seems to be relatively higher, including Beijing, Hebei, Inner Mongolia, Liaoning, Heilongjiang, Jiangsu, Shandong, Guangdong, Sichuan, Shaanxi. However, the urbanization factor only exerted little impact to the emissions in Hunan, Hainan, Chongqing, Yunnan, Gansu, Qinghai, Ningxia.
The household income has been verified to be one of the most sensible factors concerning the energy use in households sectors [31], but the influence factors and the effects vary across households in urban and rural areas. As it is shown in Fig. 6, the impact of changes in family income is quite different between urban families and rural families. In most regions, the impact of urban family income on $\mathrm{CO}_{2}$ emissions is higher than that of rural family income. The huge differences happen in those regions including Beijing, Liaoning, Jilin, Heilongjiang, Jiangsu, Guangxi, and Shaanxi. However, there are also some regions where the impact of rural family income is higher than that of urban family income, including Hebei, Shanxi, Henan, Hunan, especially Guizhou and Gansu where there

\section{The contributions of energy intensities in different sectors}

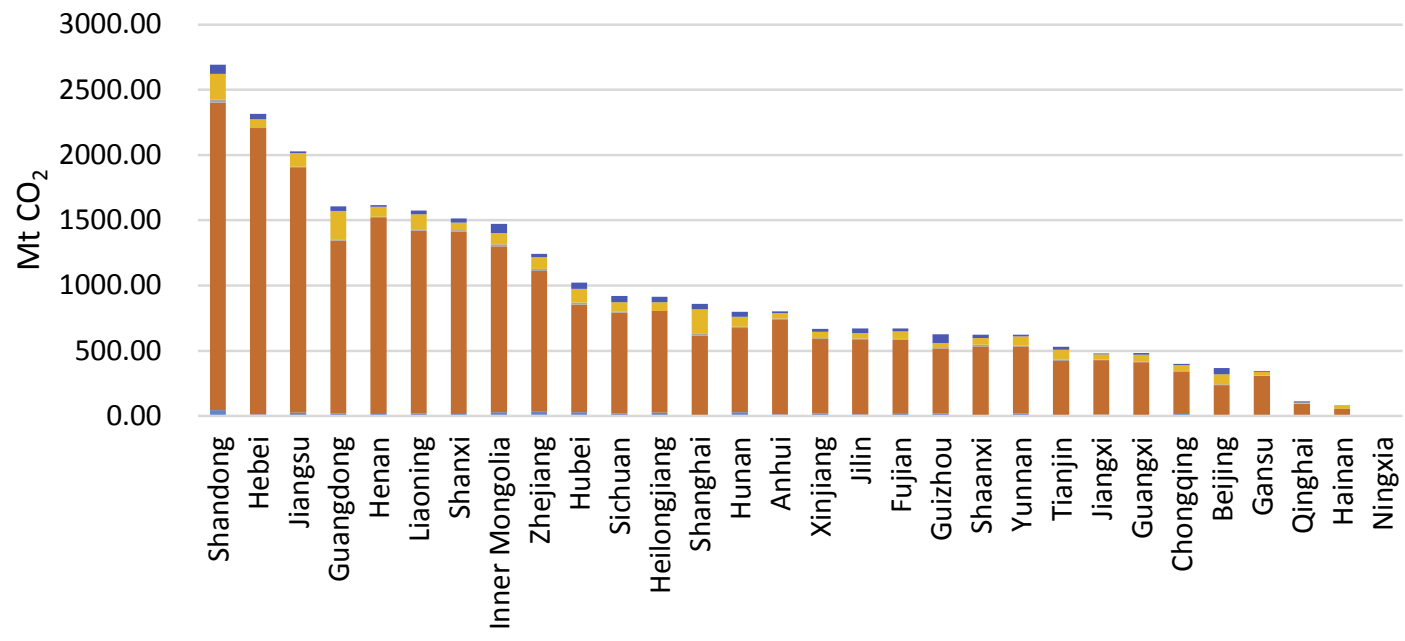

\footnotetext{
Energy Intensity of the Agricultural Sector

Energy Intensity of the Construction Sector

Energy Intensity of the Service Sector
}

Energy Intensity in the Industrial Sector

Fig. 3. The contribution of energy intensity in each sector from 2000 to 2013 . 
The contribution of energy intensity in transportation sector to the emissions in each region

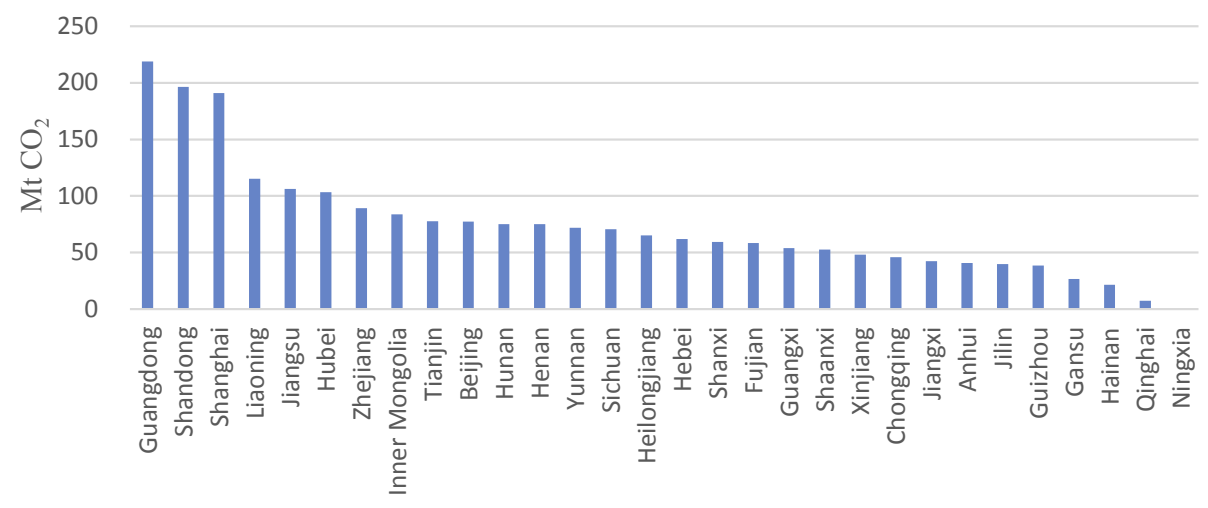

Fig. 4. The Contribution of the Transportation Sector on $\mathrm{CO}_{2}$ emission in Each Region.

the impact of rural family income is greatly higher than that of urban family income.

\section{Discussion}

According to the above empirical results, this study provides three distinct research findings as follows.

The first finding is that the contributions of energy intensity in the seven sectors on regional $\mathrm{CO}_{2}$ emissions seemed asymmetric and had distinguished trends. First, the largest contribution to regional carbon dioxide emission was made by the energy intensity in the production sector, followed by the contribution of transportation sector and business sector. The dominating role played by the production sector is consistent with the similar studies [26,30], however, another important phenomenon that should be noticed is the rapid changes in transport and business sector during the urbanization process. As the emissions in the transportation and the business sector rose rapidly, the positive effects made by both these sectors to the emissions were also increasing considerably, however, the other three sectors, production, construction, and agriculture experienced a decrease of their impacts on the emissions. Third, the contribution of agriculture sector to regional $\mathrm{CO}_{2}$ emissions consistently decreased. Specifically, the carbon dioxide emission of the primary sector in China's eastern regions was declining much faster than that in China's western regions, since the eastern regions were more advanced in the process of industrialization process and less depended on agriculture sector in their economics.

The second finding is that urbanization in China contributes to regional $\mathrm{CO}_{2}$ emissions in a variety of ways. The primary one is the change in the behavior of urban households, indicated by the results that the contribution of urban household energy use to regional $\mathrm{CO}_{2}$ emissions is almost twice as much as the contribution of rural household energy use in the highly urbanized regions like Guangdong, Beijing, and Jiangsu. Secondly, urbanization raises regional $\mathrm{CO}_{2}$ emissions by leading to increasing intensive energy use in the transport sector. Evidence shows that the transportation sector turned out to be the largest contributors in the north regions, such as Inner Mongolia, the east China areas, such as Beijing, Tianjin, and Shandong, and south areas, such as Chongqing, Yunnan, and Shaanxi, while these regions also experienced rapid urbanization. Finally, urbanization process strongly steers the industrial restructuring, resulting in higher proportion of business sector in a regional economy, which may provide great potential to a low-carbon economic paradigm.

The third finding is the regional heterogeneity in the influence mechanisms of urbanization process on regional $\mathrm{CO}_{2}$ emissions. Specifically, we found that the changing trend of these influence factors' effect on regional $\mathrm{CO}_{2}$ emissions varied across different provinces. First, in the municipalities like Beijing, Shanghai, Guangzhou, Chongqing, the contributions of transport energy intensity and GDP per capita has been seriously rising during the

\section{Contribution of urbanization to regional carbon dioxide emissions}

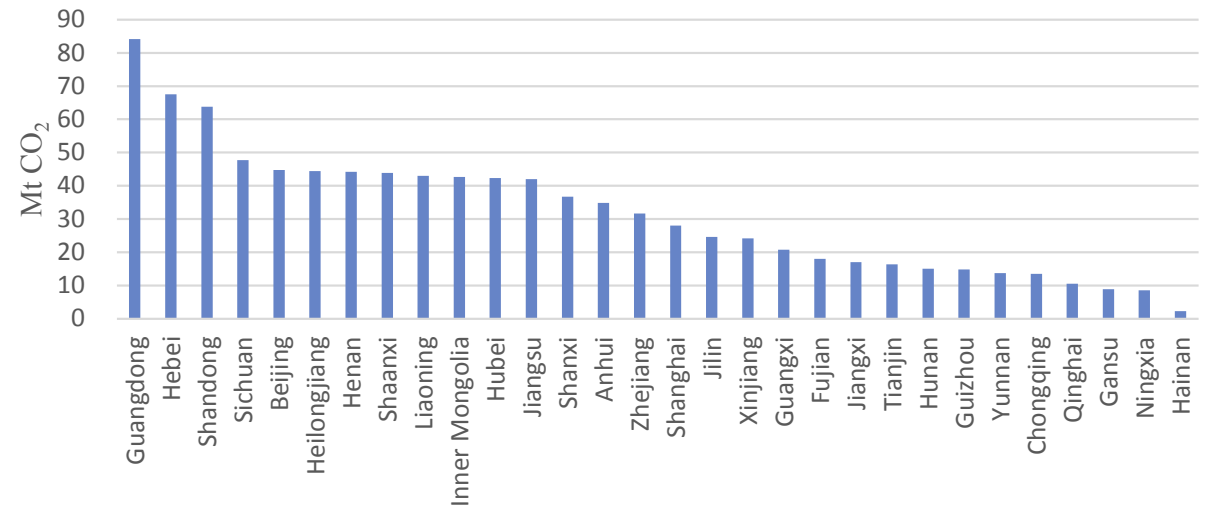

Fig. 5. The Contribution of Urbanization on $\mathrm{CO}_{2}$ emission in Each Region. 


\section{The Contribution of Average Family Income}

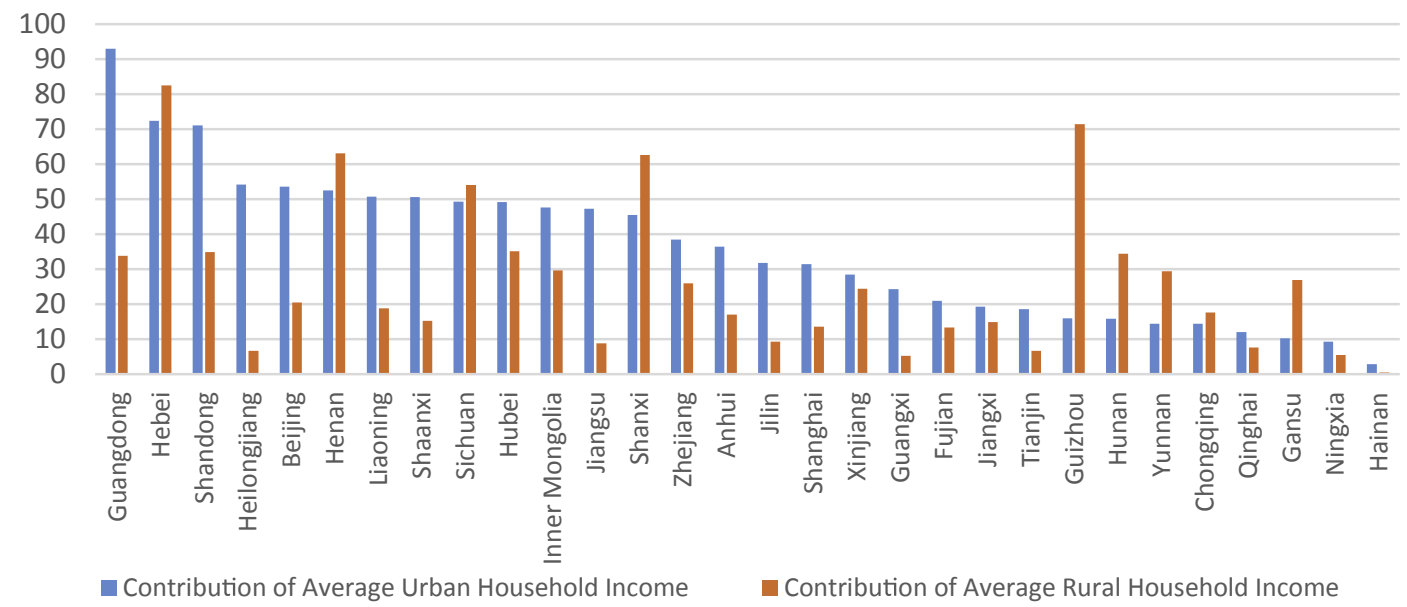

Fig. 6. The impact of average family income in urban and rural households.

study period. The empirical evidence implies that the rapid accumulation of physical and human capital in large cities took the dominant place in driving the rise of regional $\mathrm{CO}_{2}$ emissions. Second, in the regions of Central China, the contribution of business sector climbed up steadily across the period from 2000 to 2013, which indicates that the industrial restructuring played an important role in the changes in regional emissions. In 2000, the regional economic development policy for Central China, Rise of Central China Plan, was announced, including the strategic programs of specific industries, preferred technologies, and new incentives to attract investment. The analysis results of the development in Central China show that the impact of tertiary industry on regional emissions has increased significantly. Third, it is remarkable in the north-western provinces including Shaanxi, Gansu, Qinghai, Ningxia, and Xinjiang that the effect of energy structure on regional emissions started to be positive but turned to be negative in the subsequent years from 2000 to 2013. In 1999, projects focused on the infrastructure constructions of solar energy and wind power use were launched in a broad range of north-western provinces in China, providing more than 400,000 households with electricity. These projects contributed to a broader effort to develop renewable energy in rural areas in China [34].

\section{Conclusions and policy implications}

Confronted with the challenge of reduction targets in energy intensity and carbon dioxide emissions in the rapid urbanization process, a growing body of literature focuses on the relationship between urbanization and regional carbon dioxide emissions in China. This paper aims to explore the mechanisms of urbanization influence on regional $\mathrm{CO}_{2}$ emissions by clarifying the contributions of industrial sectors, residential sectors, economic development, and social transition to regional emissions and depicting the dynamic changes in the effect of various types of driving forces on regional $\mathrm{CO}_{2}$ emissions in different Chinese provinces.

There are three main findings that can be drawn from the empirical results: first, the largest contribution to regional $\mathrm{CO}_{2}$ emission was made by the energy intensity in the production, transportation, and business sector; second, urbanization in China contributes to regional $\mathrm{CO}_{2}$ emissions in a variety of ways, including changing energy use of urban households, transportation, and business sector; third, the changing trend of the contribution of social and economic factors varies across different regions in China.

The above results have important implications. In the eastern provinces, while the contribution of transportation sector and macro-economic development has been seriously rising during the study period, which implies that the rapid accumulation of physical and human capital in these regions took the dominant place in driving the rise of regional $\mathrm{CO}_{2}$ emissions. The regional policies of emission reduction should take advantage of the developed regional economics to realize the transition toward low-carbon development, which is featured by knowledge-intensive industries. In the regions of Central China, the contribution of business sector to regional emissions climbed up steadily across the period from 2000 to 2013, which indicates that the industrial restructuring plays an important role in the changes in regional emissions. Therefore, the local government should consider to exploit the potential of the tertiary industry of developing lowcarbon measures, including industrial restructuring, low-carbon lifestyle cultivation, and improving public services. In the western provinces, it is remarkable in the north-western provinces that the changes in energy structure show promising potential for regional emission reductions. Given the current poor living conditions and economic development level, policies that simply constrain the residents' energy consumption may not be appropriate, since the limits of energy use would make the residents' life even harder. Thus, the policy for western regions should emphasize the exploitation of clean energy and the corresponding infrastructure constructions.

\section{Acknowledgements}

This paper was supported by the key program of National Nature Science Foundation of China (Grant No. 71533004) and the National Natural Science Foundation of International Cooperation and Exchange Programs (Grant No. 71561137002) and the National Key Research and Development Program (Grant No. 2016YFC0502804).

\section{References}

[1] Al-mulali U, Binti Che Sab CN, Fereidouni HG. Exploring the bi-directional long run relationship between urbanization, energy consumption, and carbon dioxide emission. Energy 2012;46(1):156-67. 
[2] Ang BW. LMDI decomposition approach: a guide for implementation. Energy Policy 2015;86:233-8.

[3] Chong CH, Ma L, Li Z, Ni W, Song S. Logarithmic mean Divisia index (LMDI) decomposition of coal consumption in China based on the energy allocation diagram of coal flows. Energy 2015;85:366-78.

[4] Fernández González P, Landajo M, Presno MJ. Multilevel LMDI decomposition of changes in aggregate energy consumption. A cross country analysis in the EU-27. Energy Policy 2014a;68:576-84.

[5] Fernández González P, Landajo M, Presno MJ. Tracking European Union $\mathrm{CO}_{2}$ emissions through LMDI (logarithmic-mean Divisia index) decomposition. Energy 2014b;73:741-50.

[6] Hao H, Geng Y, Wang H, Ouyang M. Regional disparity of urban passenger transport associated GHG (greenhouse gas) emissions in China: a review. Energy 2014;68:783-93.

[7] Hasanbeigi A, Price L, Lu H, Lan W. Analysis of energy-efficiency opportunities for the cement industry in Shandong Province, China: a case study of 16 cement plants. Energy 2010;35(8):3461-73.

[8] Huang Y. Drivers of rising global energy demand: the importance of spatial lag and error dependence. Energy 2014;76:254-63.

[9] Jiang J. China's urban residential carbon emission and energy efficiency policy. Energy 2016;109:866-75.

[10] Karmellos M, Kopidou D, Diakoulaki D. A decomposition analysis of the driving factors of $\mathrm{CO}_{2}$ (Carbon dioxide) emissions from the power sector in the European Union countries. Energy 2016:94:680-92.

[11] Li H, Mu H, Zhang M, Gui S. Analysis of regional difference on impact factors of China's energy - related $\mathrm{CO}_{2}$ emissions. Energy 2012;39(1):319-26.

[12] Li K, Lin B. Impacts of urbanization and industrialization on energy consumption $\mathrm{CO}_{2}$ emissions: does the level of development matter? Renew Sustain Energy Rev 2015;52:1107-22.

[13] Lima F, Nunes ML, Cunha J, Lucena AFP. A cross-country assessment of energyrelated $\mathrm{CO}_{2}$ emissions: an extended Kaya Index Decomposition Approach. Energy 2016;115:1361-74.

[14] Lu Q Yang H, Huang X, Chuai X, Wu C. Multi-sectoral decomposition in decoupling industrial growth from carbon emissions in the developed Jiangsu Province, China. Energy 2015;82:414-25.

[15] Ma B. Does urbanization affect energy intensities across provinces in China? Long-run elasticities estimation using dynamic panels with heterogeneous slopes. Energy Econ 2015;49:390-401.

[16] Tao Y, Li F, Crittenden JC, Lu Z, Sun X. Environmental impacts of China's urbanization from 2000 to 2010 and management implications. Environ Manag 2016:57(2):498-507.

[17] Tian W, Liu Y, Heo Y, Yan D, Li Z, An J, et al. Relative importance of factors influencing building energy in urban environment. Energy 2016;111:237-50.

[18] Tian X, Geng Y, Dai H, Fujita T, Wu R, Liu Z, et al. The effects of household consumption pattern on regional development: a case study of Shanghai Energy 2016;103:49-60.

[19] Wang C, Chen JG, Zou J. Decomposition of energy-related $\mathrm{CO}_{2}$ emission in China: 1957-2000. Energy 2005;30(1):73-83.

[20] Wang P, Dai Hcheng, Ren Syan, Zhao Dqing, Masui T. Achieving Copenhagen target through carbon emission trading: economic impacts assessment in Guangdong Province of China. Energy 2015;79(C):212-27.

[21] Wang Q, Hang Y, Zhou P, Wang Y. Decoupling and attribution analysis of industrial carbon emissions in Taiwan. Energy 2016;113:728-38.

[22] Wang W, Liu X, Zhang M, Song X. Using a new generalized LMDI (logarithmic mean Divisia index) method to analyze China's energy consumption. Energy 2014;67:617-22.

[23] Wang Y, Wang Y, Zhou J, Zhu X, Lu G. Energy consumption and economic growth in China:amultivariate causality test. Energy Policy 2011;39: 4399-406.

[24] Wang Z, Zhu Y, Zhu Y, Shi Y. Energy structure change and carbon emission trends in China. Energy 2016;115:369-77.

[25] Xu B, Lin B. Differences in regional emissions in China's transport sector: determinants and reduction strategies. Energy 2016;95:459-70.

[26] Yan H. Provincial energy intensity in China: the role of urbanization. Energy Policy 2015;86:635-50.

[27] Yan Q, Zhang Q, Zou X. Decomposition analysis of carbon dioxide emissions in China's regional thermal electricity generation, 2000-2020. Energy 2016;112: 788-94.

[28] Zhang C, Lin Y. Panel estimation for urbanization,energy consumption and $\mathrm{CO}_{2}$ emissions: are regional analysis in China. Energy Policy 2012;49:488-98.

[29] Zhang M, Huang X-J. Effects of industrial restructuring on carbon reduction: an analysis of Jiangsu Province, China. Energy 2012;44(1):515-26.

[30] Zhang W, Li K, Zhou D, Zhang W, Gao H. Decomposition of intensity of energyrelated $\mathrm{CO}_{2}$ emission in Chinese provinces using the LMDI method. Energy Policy 2016;92:369-81.

[31] Zhang X, Luo L, Skitmore M. Household carbon emission research: an analytical review of measurement, influencing factors and mitigation prospects. J Clean Prod 2015:103:873-83.

[32] Zhao M, Tan LR, Zhang WG, Ji MH, Liu Y, Yu LZ. Decomposing the influencing factors of industrial carbon emissions in Shanghai using the LMDI method. Energy 2010:35:2505-10.

[33] Zhao M, Tan L, Zhang W, Ji M, Liu Y, Yu L. Decomposing the influencing factors of industrial carbon emissions in Shanghai using the LMDI method. Energy 2010;35(6):2505-10.

[34] The World Bank. Solar systems for 400,000 rural households in China. 2011 April 6. Retrieved from, http://www.worldbank.org/en/news/feature/2011/ 04/06/solar-systems-for-400000-rural-households-china. 